\title{
Multi-target action of the novel anti-Alzheimer compound CHF5074: in vivo study of long term treatment in Tg2576 mice
}

Sandra Sivilia ${ }^{1 \dagger}$, Luca Lorenzini ${ }^{1 \dagger}$, Alessandro Giuliani ${ }^{1}$, Marco Gusciglio ${ }^{1,3}$, Mercedes Fernandez², Vito Antonio Baldassarro ${ }^{2}$, Chiara Mangano ${ }^{2}$, Luca Ferraro ${ }^{3,4}$, Vladimiro Pietrini ${ }^{5}$, Maria Francesca Baroc ${ }^{5}$, Arturo R Viscomi ${ }^{6,8}$, Simone Ottonello ${ }^{6}$, Gino Villetti ${ }^{7}$, Bruno P Imbimbo ${ }^{7}$, Laura Calzà ${ }^{2,3^{*}}$ and Luciana Giardino ${ }^{2,3}$

\begin{abstract}
Background: Alzheimer disease is a multifactorial disorder characterized by the progressive deterioration of neuronal networks. The pathological hallmarks includes extracellular amyloid plaques and intraneuronal neurofibrillary tangles, but the primary cause is only partially understood. Thus, there is growing interest in developing agents that might target multiple mechanisms leading to neuronal degeneration. CHF5074 is a nonsteroidal anti-inflammatory derivative that has been shown to behave as a $\gamma$-secretase modulator in vitro and to inhibit plaque deposition and to reverse memory deficit in vivo in transgenic mouse models of Alzheimer's disease (AD). In the present study, the effects of a long-term (13-month) treatment with CHF5074 on indicators of brain functionality and neurodegeneration in transgenic AD mice (Tg2576) have been assessed and compared with those induced by a prototypical $\gamma$-secretase inhibitor (DAPT).

Results: To this end, plaque-free, 6-month-old Tg2576 mice and wild-type littermates were fed with a diet containing CHF5074 (125 and 375 ppm/day), DAPT (375 ppm/day) or vehicle for 13 months. The measured indicators included object recognition memory, amyloid burden, brain oligomeric and plasma A $\beta$ levels, intraneuronal A $\beta$, dendritic spine density/morphology, neuronal cyclin A positivity and activated microglia. Tg2576 mice fed with standard diet displayed an impairment of recognition memory. This deficit was completely reverted by the higher dose of CHF5074, while no effects were observed in DAPT-treated mice. Similarly, amyloid plaque burden, microglia activation and aberrant cell cycle events were significantly affected by CHF5074, but not DAPT, treatment. Both CHF5074 and DAPT reduced intraneuronal $A \beta$ content, also increasing A $\beta 40$ and $A \beta 42$ plasma levels.
\end{abstract}

Conclusions: This comparative analysis revealed a profoundly diverse range of clinically relevant effects differentiating the multifunctional anti-inflammatory derivative CHF5074 from the $\gamma$-secretase inhibitor DAPT and highlighted unique mechanisms and potential targets that may be crucial for neuroprotection in mouse models of $A D$.

Keywords: Alzheimer's disease, Cell-cycle events, CHF5074, Dendrite pathology, Tg2576 mice

\footnotetext{
* Correspondence: laura.calza@unibo.it

${ }^{\dagger}$ Equal contributors

${ }^{2}$ Health Science and Technologies Interdepartmental Center for Industrial

Research (HST-ICIR), University of Bologna, Via Tolara di Sopra 50, Bologna, Ozzano Emilia I-40064, Italy

${ }^{3}$ IRET Foundation, Via Tolara di Sopra 50, Bologna, Ozzano Emilia 40064, Italy

Full list of author information is available at the end of the article
} 


\section{Background}

Extracellular amyloid plaques formed by aggregated $\beta$-amyloid $(A \beta)$ peptides and intracellular neurofibrillary tangles are the landmarks of Alzheimer's disease (AD) pathology [1]. Studies relying on familial AD patients with mutations in the A $\beta$ (amyloid) precursor protein APP, or the catalytic subunits of the $\gamma$-secretase complex responsible for the second (A $\beta$-generating) step of APP processing yielded the so-called " $\beta$-amyloid cascade hypothesis" of $\mathrm{AD}$. Recently, this etiopathogenetic hypothesis, which in its latest formulation holds $A \beta$ oligomers as the most proximal cause of $\mathrm{AD}$ neurodegeneration [2], is facing the failure of multiple clinical trials carried out with various drugs targeting $A \beta$ accumulation in the brain [3]. These include active and passive anti-A $\beta$ vaccines, but also $\gamma$-secretase inhibitors and modulators, and $A \beta$ aggregation inhibitors [4-7]. Additional abnormalities not so closely related to $\mathrm{A} \beta$ accumulation/overproduction per se (e.g. altered intraneuronal APP metabolism and trafficking) [8-10] and other derailed cellular processes whose precise causal relationship with $A \beta$ remains to be elucidated, have been described in the AD brain. The multifaceted cellular dysregulation associated with $\mathrm{AD}$ neurodegeneration, possibly also leading to cortical atrophy, includes tau protein hyperphosphorylation, neuronal cell death, neuroinflammation, neurite abnormalities, synapse and dendritic spine loss [10-16]. Thus, the search for new (and effective) AD therapies needs to address additional targets other than just amyloid clearance and to focus on early prevention of neurodegeneration.

CHF5074 [1-(3',4'-dichloro-2-fluoro[1,1'-biphenyl]-4yl)-cyclopropanecarboxylic acid] is a nonsteroidal anti-inflammatory derivative devoid of cyclooxygenase inhibitory activity. In vitro, CHF5074 behaves as a $\gamma$ secretase modulator preferentially inhibiting $A \beta 42$ production, without affecting neither the processing of the C-terminal portion of APP, nor $\gamma$-secretase-mediated Notch processing [17-19]. CHF5074 has been shown to inhibit brain plaque deposition and to attenuate or reverse contextual and spatial memory deficit in different transgenic mouse models of $\mathrm{AD}$, also reversing long-term potentiation deficit in the hippocampus [20-22]. However, recent data have shown that CHF5074 is able to promote axon growth and astrocyte plasticity by modulating Rho-GTPase-dependent signaling [23], thus suggesting that the range of biological actions exerted by this compound may be wider than expected. In the present in vivo and ex-vivo study, we evaluated the effect of a long-term treatment with CHF5074 on cognitive performance and on several neuronal dysfunction markers in the Tg2576 mouse model of AD. The effects of CHF5074 were compared with those of DAPT ( $\mathrm{N}$-[N-(3,5-difluorophenacetyl)-L-alanyl]-S-phenylglycine t-butyl ester), a prototypical $\gamma$-secretase inhibitor [24]. Drug treatments were started at 6 months of age when no plaques are detectable [25], and were carried on in a chronic fashion till a very late age (19 months), which is close to the life expectancy of $\operatorname{Tg} 2576$ mice. A recognition memory test was carried out before the analysis of several distinct post-mortem indicators of brain functionality and neurodegeneration.

\section{Methods}

\section{Animals and treatments}

Tg2576 transgenic mice carry a transgene coding for the 695-amino acid isoform of human APP derived from a large Swedish family with early-onset AD [25]. These mice express high concentrations of the mutant $A \beta$, develop significant number of amyloid plaques and display memory deficits. $\operatorname{Tg} 2576$ mice and their non-transgenic littermates (001349-W), which served as controls, were purchased from Taconic Europe (Lille Skensved, Denmark). Mice were all genotyped for retinal degeneration.

Six-months-old transgenic females and aged-matched non-transgenic littermates were used. Transgenic and nontransgenic mice $(\mathrm{N}=17-27$ per treatment group) were treated for 13 months with CHF5074 (125 and 375 ppm in the diet), DAPT (375 ppm/day in the diet) or standard diet (herafter designated as "vehicle"). CHF5074- and DAPTmedicated diets were provided by Mucedola (Settimo Milanese, Italy). The estimated ingested doses of CHF5074 were about 20 and $60 \mathrm{mg} / \mathrm{kg} /$ day (behaviourally effective dose when given chronically for 9 months) [21]; the estimated ingested dose of DAPT was about $60 \mathrm{mg} / \mathrm{kg} /$ day. The dose of DAPT was selected based on previous studies showing that the drug given orally at doses ranging from 10 to $100 \mathrm{mg} / \mathrm{kg}$ dose-dependently inhibited cortical $A \beta$ levels in hAPP transgenic mice [26]. After behavioural testing, mice were sacrificed and their brains were split in the two hemispheres. The left hemisphere was divided into anterior and posterior parts at level -0.70 according to the Paxinos and Franklin atlas of the mouse brain [27]. The anterior part, containing the olfactory bulb, was quickly frozen into liquid $\mathrm{N} 2$, while the posterior part, including the hippocampus, was fixed for amyloid plaque and $A \beta$ oligomer analysis. The right hemisphere was divided as above and fixed for immunohistochemistry (anterior part) and Golgi-Cox staining (posterior part, including the hippocampus). Animal care and treatments were in accordance with the EU Directive 2010/63/EU for animal experiments and in conformity with protocols approved by the Ethical Committee of Animal Experimentation, University of Bologna.

\section{Novel object recognition test (NOR)}

Long-term memory was evaluated in 18 months-old mice using NOR, measuring recognition memory under spontaneous behavioural conditions. Before NOR, all animals were tested for the papillary reflex and only 
positive animals were included in the study. Mice were tested in an open-square grey arena (46 x $46 \mathrm{~cm}), 30 \mathrm{~cm}$ high (Ugo Basile, Comerio, Italy). The task started with a habituation trial in which the animals were placed into the empty arena for $10 \mathrm{~min}$. The next day, mice were placed into the same arena containing two identical objects (familiarization phase). In order to evidence side preferences, exploring times spent on left and right familiar objects were recorded separately. The exploratory behaviour was analyzed by calculating the investigation time on both objects. Sniffing and touching the object at a distance not greater than $2 \mathrm{~cm}$ were scored as object investigation. Four hours later (test trial) mice were placed in the arena containing one object identical to the one presented during the familiarization phase (familiar object), and a new one (novel object); the time spent exploring the two objects was recorded for $10 \mathrm{~min}$. The videotracking software AnyMaze (Stoelting, Wood Dale, Illinois) was used for analysis. Memory was expressed as recognition index: (seconds on novel - seconds on familiar)/(total time on objects). Animals with no memory impairment spent longer time investigating the novel object, giving a higher discrimination index.

\section{Golgi-Cox staining}

FD Rapid GolgiStain ${ }^{\text {TM }}$ Kit (FD NeuroTechnologies, Ellicott City, MD, USA) was used for detailed morphological analysis of dendritic spines. Tissue was rapidly frozen, cut on a cryostat and mounted on gelatin-coated microscope slides. Sections were processed with the NDT104 FD Rapid GolgiStain ${ }^{\mathrm{TM}}$ Kit. For each mouse, ten fully impregnated hippocampal CA1 neurons were identified under low magnification $(20 \times, 0.5 \mathrm{NA})$. The acceptance criteria for spines were according to Middei et al. [28]. Dendritic spines were measured under high magnification $(100 \times, 1.25 \mathrm{NA})$ from images acquired using a digital camera (Olympus F-View). Measurements were performed on secondary and tertiary branches of CA1 basal dendrites irrespective of their orientation. On each neuron, at least five dendritic spines were selected according to the criteria proposed by Knafo et al. [29]: only considering spines separated throughout their entire length from neighbour spines or dendrites and excluding spine-like protrusions with bifurcated heads or with heads longer than $3.5 \mu \mathrm{m}$. Spine length was defined as the distance from the dendritic shaft to the tip of the spine.

\section{Immunohistochemistry and image analysis}

Indirect immunofluorescence was used to determine immunoreactivity associated with intracellular $\mathrm{A} \beta$, cyclin $\mathrm{A}$, NeuN. Brain tissue was immersed in $4 \%$ paraformaldehyde for 24 hours and then washed in $5 \%$ sucrose in phosphate buffer. Sections $(14 \mu \mathrm{m}$ thick) were cut with a cryostat to include the medial cortex. The following primary antibodies were used: $6 \mathrm{E} 10$ anti-A $\beta_{1-16}$ monoclonal antibody (Covance, Princeton, NJ) for APP/A $\beta$ (this antibody reacts with the $\mathrm{SAPP} \beta$ precursor as well as with the processed forms of $A \beta$ ) at a 1:1000 dilution; 4G8 anti-A $\beta$ 17-24 monoclonal antibody (Covance) for $\mathrm{APP} / \mathrm{A} \beta$ (this antibody reacts with the SAPP $\beta$ precursor as well as with the processed forms of $A \beta$ ) at a 1:800 dilution; rabbit anti Cyclin A (ab7956, AbCam, Cambridge, UK) diluted 1:200; mouse anti neuronal nuclei antibody (NeuN, MAB377 Chemicon) diluted 1:200. Appropriate Rhodamine Red$\mathrm{X}$-and FITC-conjugated secondary antibodies were used for detection (Jackson ImmunoResearch, Baltimore, PA).

For intraneuronal $\mathrm{A} \beta$ immunostaining, about 50 neurons in the anterior cingulated cortex were analyzed for each animal. Stained specimens were analyzed with a Nikon 600 Eclipse microscope equipped with a Nikon DXM1200F digital camera (Nikon Italia, Florence, Italy). The ProPlus software (Media Cybernetics Inc, Bethesda, MD) was used to evaluate optical density in single cells. The expression of cell cycle proteins was analyzed in two sections/animal, in both genotypes. NeuN-positive cells were scored within layers II/III of the frontal cortex, and the percentage of cyclinA immunoreactive, NeuN-positive cells was recorded [30]. For all markers, the mean value/animal was used for statistical analysis. All analyses were performed in a blinded manner.

\section{Brain $\beta$-amyloid plaques and activated microglia}

Brain samples corresponding to the posterior half of the left hemisphere were used for quantitative analysis of plaques and activated microglia. They were fixed in $10 \%$ formalin and then embedded in paraffin according to a standard procedure. Coronal sections (10 $\mu \mathrm{m}$ thick) ranged from bregma $-1.46 \mathrm{~mm}$ (anterior) to $-2.06 \mathrm{~mm}$ (posterior) [27]. A $\beta$ plaque immunohistochemistry was performed using the biotinylated 6E10 monoclonal antibody (Signet Laboratories, Dedham, MA) diluted 1.250 as primary antibody. Pretreatments were: incubation in a $3 \% \mathrm{H}_{2} \mathrm{O}_{2}$ solution in distilled water for 15 minutes to block endogenous peroxidase; incubation in $80 \%$ formic acid for 30 minutes for antigen retrieval. After rinsing in TBS for 10 minutes, sections were incubated overnight at $4^{\circ} \mathrm{C}$ in a humid atmosphere with the primary antibody diluted in TBS containing $0.3 \%$ Triton X-100. After rinsing in TBS for $10 \mathrm{~min}$, sections were incubated for $60 \mathrm{~min}$ in a humid atmosphere with the streptavidinperoxidase solution, according to the mouse-on-mouse kit procedure (Dako Cytomation, Glostrup, Denmark) using a peroxidase-based revealing system. Peroxidase activity was detected by treatment with 3,3'-diaminobenzidine (DAB) for 5 minutes. Slides were photographed using a digital Nikon DS microscope colour camera. Digital images were analyzed using NIS-Elements software (Nikon, Tokyo, Japan). Each image was analyzed using the automated 
target detection mode. Imagesize was 1280 x 960 pixels with a target area size of $68,000 \mu \mathrm{m}^{2}$. The software determined the number of plaques, the plaque mean area and the plaque area fraction (immunopositive area/total area used as scan object). Twelve counts were performed for each of the two levels considered. Analyses were performed in analogous areas of the cortex and hippocampus using a 10x objective.

Activated microglia in CA1 region of hippocampus was immunodetected using the Iba1 Rabbit polyclonal antibody (Biocare, Concord, CA). A 20x objective and a target area of $16,900 \mu \mathrm{m}^{2}$ was used for this analysis, which involved three counts in homologous areas of CA1 region of hippocampus. After rinsing in distilled water, sections were incubated in a $3 \% \mathrm{H}_{2} \mathrm{O}_{2}$ solution in distilled water for 15 minutes. After rinsing in TBS for 10 minutes, sections were incubated for 30 minutes with normal goat serum diluted 1:20 with TBS. The sections were then incubated overnight at $4^{\circ} \mathrm{C}$ in a humid atmosphere with the primary Iba1 antibody diluted 1:250 with TBS. After rinsing in TBS for $10 \mathrm{~min}$, sections were incubated for $60 \mathrm{~min}$ in a humid atmosphere with the secondary antibody solution provided by the Goat anti Rabbit Envision System (Dako, Denmark) diluted 1:1 with TBS. Peroxidase activity was detected by treatment with DAB.

\section{Brain $A \beta$ oligomers}

$A \beta$ oligomers were determined in low-detergent $(0.1 \%$ Triton-X100, $0.01 \%$ Nonidet-P40) and high-detergent (3\% SDS, $0.5 \%$ Triton X-100, 1\% deoxycholate) extracts prepared from left hemi-forebrains specimens as described by Lesné et al. [31] with slight modifications. These included cumulative extraction $(50 \mathrm{mM}$ Tris$\mathrm{HCl}, \mathrm{pH}$ 7.6, $150 \mathrm{mM} \mathrm{NaCl}, 2 \mathrm{mM}$ EDTA, 0.01\% NP40, $0.1 \%$ Triton $\mathrm{X}-100$, plus $1 \mathrm{mM}$ phenylmethylsulfonyl fluoride) and mixing of the soluble (extracellularenriched) and cytoplasmic fractions, and the omission of the endogenous immunoglobulin depletion step in order to avoid any artefactual modification of the samples. The residual pellet remaining after low-detergent extraction was further extracted by gentle agitation in $200 \mu \mathrm{l}$ of a buffer solution containing $50 \mathrm{mM}$ Tris- $\mathrm{HCl}$ ( $\mathrm{pH} 7.4$ ), $150 \mathrm{mM} \mathrm{NaCl}, 0.5 \%$ Triton X-100, $1 \mathrm{mM}$ EDTA, 3\% SDS, $1 \%$ deoxycholate and $1 \mathrm{mM}$ PMSF, followed by centrifugation for $90 \mathrm{~min}$ at 13,000 rpm. Total protein content of each extract was determined in triplicate with the Bradford Protein Assay reagent (Bio-Rad) using bovine serum albumin as standard; the average of the resulting values (differing by less than $5 \%$ of the mean) was used to balance sample input for immunoblot analysis. All extractions were performed in three experimental sessions, carried out at three-days intervals on randomized subsets of the various brain samples, and the resulting extracts (a total of 65) were flash-frozen in dry ice and stored at $-80^{\circ} \mathrm{C}$. For immunoelectrophoretic analysis, brain extracts $(100 \mu \mathrm{g}$ or $50 \mu \mathrm{g}$ total protein/ each for the low-detergent and the high-detergent extracts, respectively) were heated for $15 \mathrm{~min}$ at $70^{\circ} \mathrm{C}$ in sample buffer and electrophoresed on pre-cast $4-12 \%$ Bis-Tris Midi gradient gels (Invitrogen). Gel-fractionated proteins were electro-transferred to $0.2 \mu \mathrm{m}$ nitrocellulose membranes, which were boiled for $25 \mathrm{sec}$ in PBS, soaked for $10 \mathrm{~min}$ in PBS containing $100 \mathrm{mM}$ $\beta$-mercaptoethanol and $0.1 \%$ SDS, washed three times (10 min each) with PBS and blocked with $5 \%$ bovine serum albumin in Tris-buffered saline, prior to antibody addition and incubation using the Snap i.d. blotting system (Millipore). The 6E10 monoclonal antibody (diluted 1:500) was used for immunodetection. Antigen-antibody complexes were revealed with a goat anti-mouse, IrDye 680-labeled secondary antibody (LI-COR; diluted 1:3000), followed by visualization and quantification of immunereactive bands by near-infrared fluorescence with an Odyssey imager (LI-COR). A total of 14 independent sets of analyses, each comprising 10 sample extracts with at least one vehicle-treated wild-type control, were performed. Non-specific, 6E10 mAb cross-reactive polypeptides, present in both wild-type and $\mathrm{Tg} 2576$ brain extracts, were used as loading controls and internal references for data normalization. Synthetic prefibrillar $A \beta 42(n)$ prepared according to Lambert et al. [32], with $n$-values ranging from 1 to 4 , was used as size standard for electrophoretic analysis. Results, expressed as NIRF arbitrary units, were analyzed with the SigmaStat ${ }^{\mathrm{Tm}}$ software and are presented as mean \pm standard error of the mean (SEM).

\section{$A \beta 40$ and $A \beta 42$ plasma levels}

At the time of sacrifice, blood samples were collected in EDTA-vacuum collection tubes, centrifuged at $4000 \mathrm{~g}$ for $10 \mathrm{~min}$ and plasma aliquots were stored at $-80^{\circ} \mathrm{C}$. Simultaneous quantification of $\beta$-amyloid $1-40$ (A $\beta 40)$ and $\beta$-amyloid 1-42 $(\mathrm{A} \beta 42)$ peptides was performed on properly diluted plasma samples using the INNO-BIA plasma $\mathrm{A} ß$ forms kit (Innogenetics NV, Gent, Belgium, through Innogenetics srl, Italy), following the manufacturer's instructions. This kit is a fluorimetric bead-based immunoassay using Luminex $\mathrm{xMAP}^{\circledR}$ technology. Briefly, the $A \beta 40$ and $A \beta 42$ peptides are captured selectively by a mix of beads (xMAP ${ }^{\circledR}$ microspheres) coated with three monoclonal antibodies (mAb): $21 \mathrm{~F} 12$ for A $442,2 \mathrm{G} 3$ for $\mathrm{A} \beta 40$ and AT120 for matrix. Following an overnight incubation step at $4^{\circ} \mathrm{C}$, the mix is washed and subsequently incubated with the "detection conjugate" solution (phycoerythrin-labeled streptavidin) at room temperature for $1 \mathrm{~h}$. The mix of beads is then washed and read using the Luminex ${ }^{\circledR} 100^{\mathrm{TM}}$ IS Total System, which analyzes the microspheres/beads in a flow stream. The fluorescence 
signals associated with individual beads are converted into intensity units by a digital signal processor and then related to the concentration of the bound antigen through the Luminex IS 2.3 software.

\section{Statistical analysis}

Data were analyzed with the appropriate model of analysis of variance (ANOVA) depending on the type of variable. Behavioural data were analyzed with two-way analysis of variance with "genotype" (non-transgenic and Tg2576) and "treatment" (vehicle, CHF5074/DAPT) as fixed factors and mouse as random factor. For balanced design (object recognition task), the ANOVA model also included "genotype by treatment" as fixed factor. To reduce the loss of power due to multiple testing post hoc comparisons were only directed toward the transgenic control group (Tg2576-vehicle) and were carried out with the Holm-Sidak's test. Two-tailed $p$ values were calculated. Calculations were performed with the statistical software SigmaStat ${ }^{\mathrm{Tm}}$ (Version 3.5, SPSS, Chicago, IL). Results were generally presented as mean \pm standard error of the mean (SEM).

\section{Results}

\section{Drug tolerability}

Total mortality during the 13 months-time period of the present study was $28 \%$ and $15 \%$ for $\mathrm{Tg} 2576$ mice and wild-type animals, respectively (Figure 1). Mortalities in vehicle-, CHF5074 (375 ppm/day)- and DAPT (375 ppm/day)-treated wild-type animals were 15\%, 15\% and $30 \%$, respectively. The corresponding values for vehicle-, CHF5074 (125 ppm/day)-, CHF5074 (375 ppm/ day)- and DAPT (375 ppm/day)-treated Tg2576 mice were $29 \%, 28 \%, 28 \%$ and $47 \%$, respectively. Mortality was not statistically different among treatment groups. Overall, CHF5074 and DAPT, continuously administered for 13 months, appeared to be well tolerated by both wild-type and Tg2576 animals.

\section{Object recognition memory performance of 18-months-old Tg2576 mice chronically treated with CHF5074 or DAPT}

Object recognition memory, measured by the novel object recognition (NOR) task after 12 months of drug treatment, was evaluated as a first indicator of CHF5074 efficacy. As shown in Figure 1, compared to wild-type animals, Tg2576 mice fed with standard diet ("vehicle") displayed a borderline significant impairment of recognition memory $(p=$ 0.052). This impairment was fully recovered in transgenic animals chronically treated with the higher dose of CHF5074 (375 ppm/day; $p=0.031$ ), while it was not significantly modified by the lower dose of CHF5074 (125 ppm/ day; $p=0.101)$. CHF5074 treatment did not affect recognition memory in wild-type mice. Chronic treatment with DAPT (375 ppm/day) did not affect the NOR performance of either wild-type (data not shown) or Tg2576 mice.

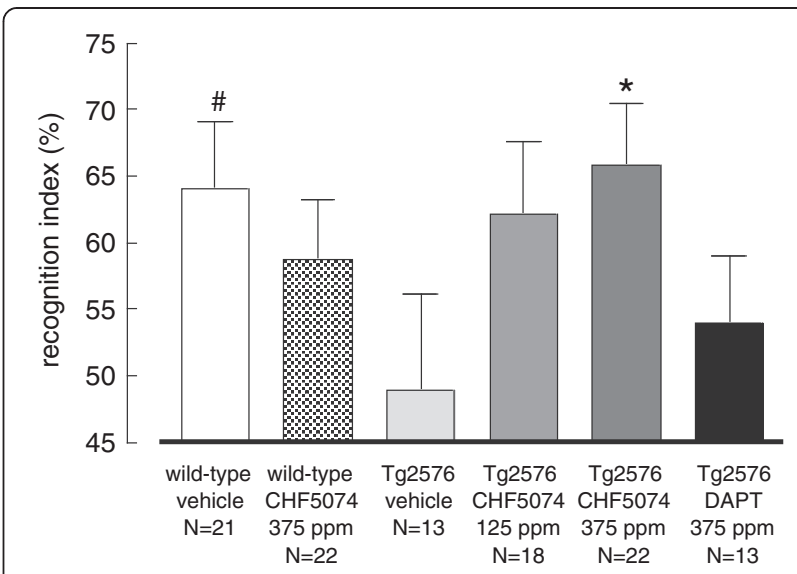

Figure 1 Novel object recognition memory in the different treatment groups. Bars represent the average $( \pm$ SEM) of the recognition index in the novel object recognition task. Vehicletreated Tg2576 mice showed a borderline significant impairment of recognition compared to control non-transgenic mice treated with vehicle ( $p=0.052)$. CHF5074-treatment (375 ppm) completely reversed memory impairment in Tg2576 mice $(p=0.031)$. DAPT was ineffective both in Tg2576 and wild-type animals (wild type not shown). The number of animals included in each group is indicated under the corresponding bar. ${ }^{*} p<0.05$ and \# $p=0.052$ vs vehicletreated Tg2576 mice.

Exploration time among the experimental groups was not different in the training period (one way ANOVA, $\mathrm{p}=p=$ 0.365).

To exclude possible alterations of either motor or exploratory behaviour as possible influencing factors, the mean speed relcorded during the $10 \mathrm{~min}$ habituation trial in the empty arena, and the total object exploration time during the familiarization phase were also analyzed. $\operatorname{Tg} 2576$ mice treated with both doses of CHF5074 displayed a significant $(p<0.01)$ reduction in the mean speed when compared to vehicle-treated mice $(3.42 \pm 0.64$, $2.13 \pm 0.24$ and $2.19 \pm 0.23 \mathrm{~m} / \mathrm{min}$ after vehicle, CHF5074 125 and CHF5074 375 ppm/day, respectively). However, this effect was not associated with significant differences in total time in movement $(494 \pm 26,474 \pm 28$ and $511 \pm 15 \mathrm{sec}$ after vehicle, CHF5074 125 and $375 \mathrm{ppm} /$ day, respectively). Neither CHF5074 nor DAPT significantly affected the mean speed $(1.88 \pm 0.18,2.31 \pm 0.18$ and $1.72 \pm 0.18 \mathrm{~m} / \mathrm{min}$ after vehicle, CHF5074 $375 \mathrm{ppm} /$ day and DAPT $375 \mathrm{ppm} /$ day, respectively) or the total time in movement $(470 \pm 19,514 \pm 14$ and $459 \pm 20$ sec after vehicle, CHF5074 $375 \mathrm{ppm} /$ day and DAPT $375 \mathrm{ppm} /$ day, respectively) of wild-type animals.

\section{Amyloid plaque burden, intraneuronal $A \beta$ and $A \beta$ clearance in the brain of 18-months-old Tg2576 mice chronically treated with CHF5074 or DAPT}

Amyloid plaque burden was visualized with the anti-A $\beta_{1-16}$ monoclonal antibody (mAb) 6E10 (Figure 2A-F; Additional 


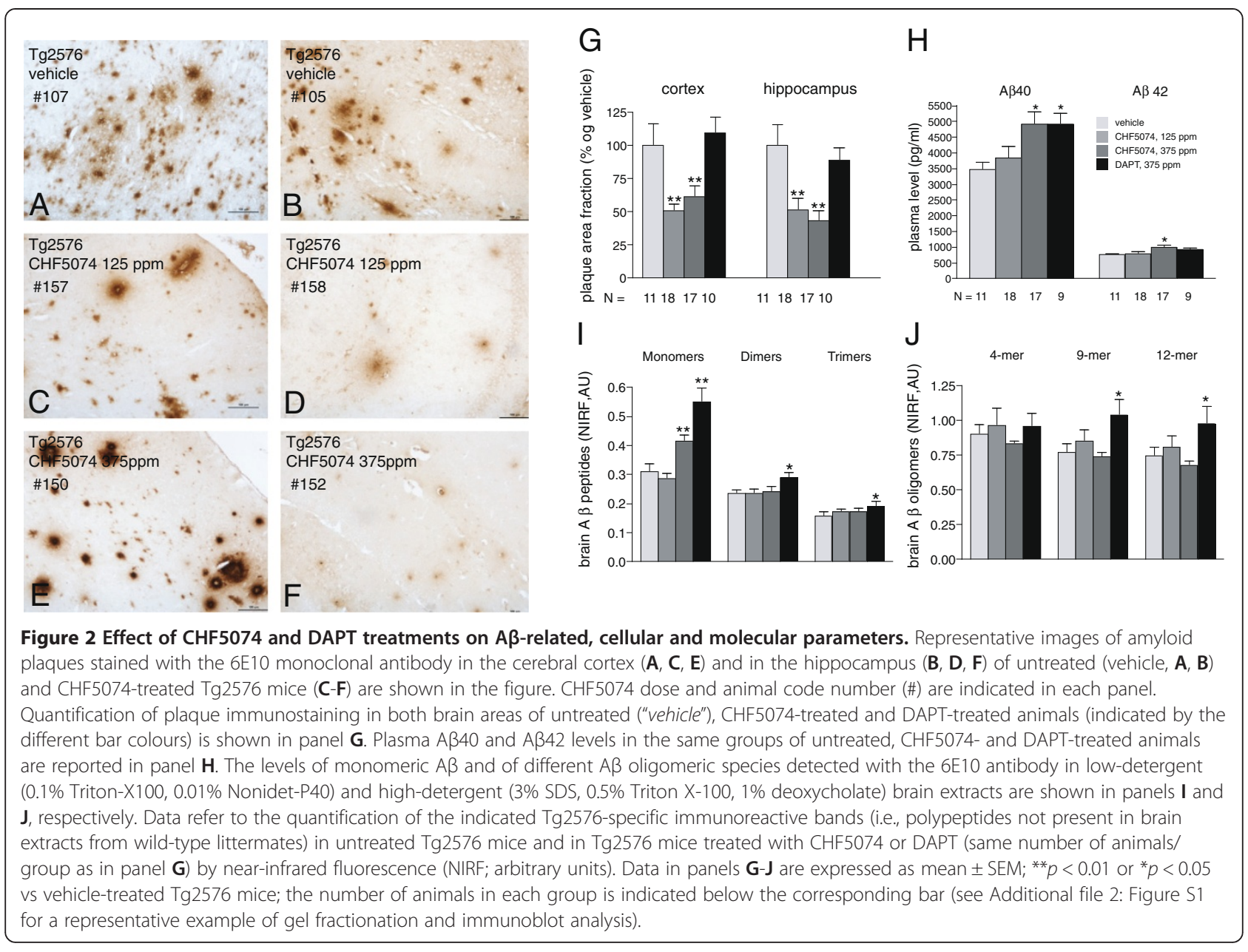

file 1: Figure S2) and was semi-quantitatively determined by digital image analysis of coronal brain sections derived from the cortex and the hippocampus (Figure 2G). CHF5074 treatment modified both the amount and the distribution of amyloid plaques. Despite a higher plaque abundance in the cortex compared to the hippocampus, at either dose it caused a nearly $50 \%$ reduction of the plaque area fraction in both brain regions. Quantification of the immunoreactivity revealed a significantly lowered plaque area fraction in CHF5074-treated animals compared to control mice, both in the cortex $(-61.0 \pm 5.1 \%, \mathrm{p}<0.001$ and $-48.2 \pm$ $8.9 \%, \mathrm{p}=0.003$ in the 125 and $375 \mathrm{ppm} /$ day-treated groups, respectively) and in the hippocampus $(-52.3 \pm 9.4 \%$, $\mathrm{p}=0.007$ and $-64.9 \pm 8.1 \%, \mathrm{p}=0.001$ in the 125 and $375 \mathrm{ppm} /$ day-treated groups, respectively). DAPT treatment did not affect plaque burden.

In contrast, as further shown in Figure 2 (panels I, J), no significant effect of CHF5074 treatment was observed on brain $A \beta$ oligomers (see Additional file 2: Figure S1 for a representative example of gel fractionation and immunoblot analysis). The only significant change revealed by this analysis was an increase of brain monomeric $A \beta$ levels in Tg2576 mice treated with the higher dose of CHF5074, which was associated with increased plasma levels of both $A \beta 40$ and $A \beta 42$ (Figure $2 \mathrm{H}$ ). An even higher increase of brain $A \beta$ monomer levels was observed upon treatment with DAPT, which also caused a significant elevation of $\mathrm{A} \beta$ oligomeric species migrating as dimers, trimers and nonamers, and a slight (borderline significant) increase of 12-mers (Figure 2I, J).

Intraneuronal A $\beta$ (APP) levels were assessed using mAb 6E10 and 4G8 as detection reagent. Representative images of brain cortex specimens stained using $\mathrm{mAb}$ 6E10 derived from untreated (panel A; "vehicle") and CHF5074-treated (panels B, C; 125 and 375 ppm) mice are shown in Figure 3. A paper by Aho et al. [33] directly compared all commercially available monoclonal antibodies in post-mortem Alzheimer brain tissues, concluding that intracellular labeling was readily apparent when using 6E10 and that both 6E10 and 4G8 antibodies failed to distinguish $\mathrm{A} \beta$ peptides from APP. According to these findings, we will use the term "6E10immunoreactivity" to describe the results obtained with this antibody. Mean (background subtracted) optical 


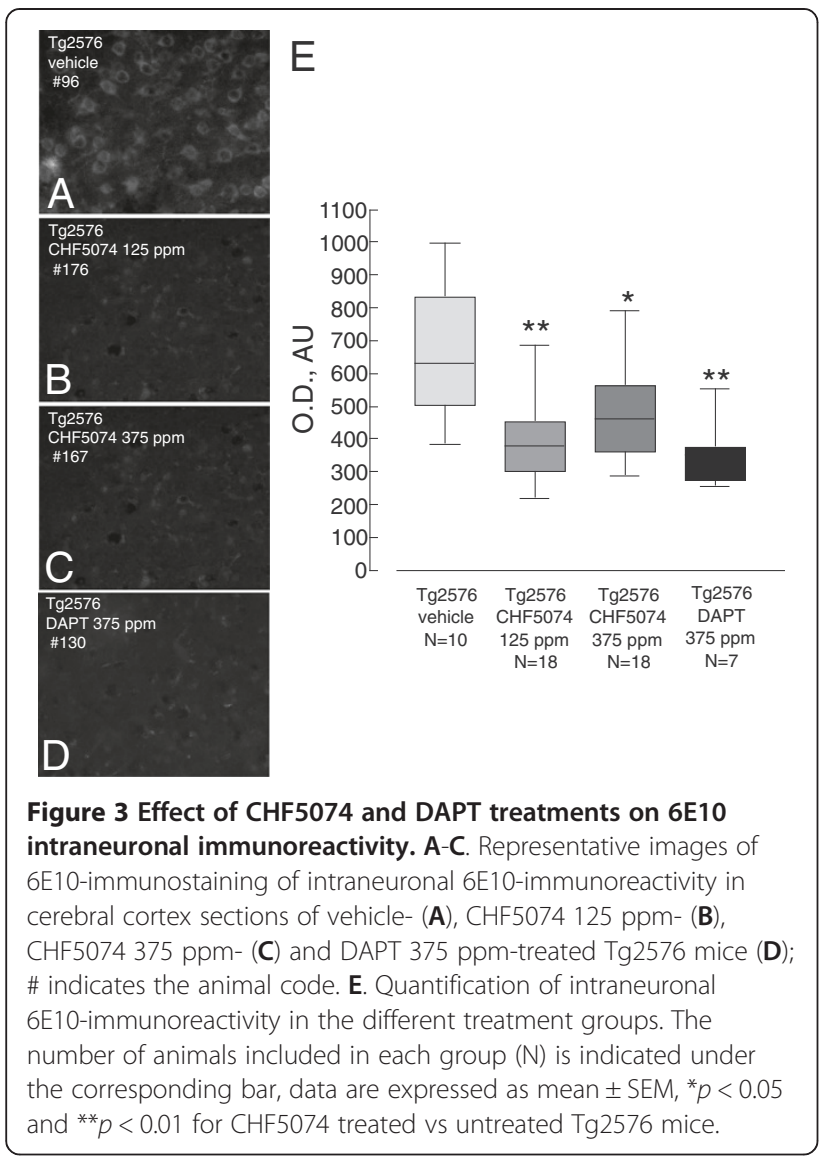

density values derived from at least 50 neurons/animal sampled in the anterior cingulated cortex were used for statistical analysis. As revealed by this analysis (Figure 3D), 6E10-immunoreactivity was significantly lower in $\operatorname{Tg} 2576$ mice treated with either dose of CHF5074 (-33.5 $\pm 7.3 \%$, $\mathrm{p}<0.01 ;-27.1 \pm 4.9 \%, \mathrm{p}<0.01)$ or DAPT $(-44+10.6$, $\mathrm{p}<0.01)$ than in vehicle-treated animals. The same results were obtained using 4 G8 antibody (data not shown).

\section{Anti-neuroinflammatory properties and possible downstream effects of chronic treatment with CHF5074 or DAPT \\ Microglia activation}

Microglia activation was investigated with the use of an antibody targeting the glia-specific calcium-binding adaptor protein Iba1. Representative images of the hippocampal CA1 region from vehicle- and CHF5074-treated transgenic mice are shown in Figure 4 (panels A-D; Additional file 1: Figure S2). Activated, immunopositive microglia was lower $(-66.3 \pm 5.3 \% p<0.001)$ in wild-type animals than in control, vehicle-treated Tg2576 mice. Interestingly, compared to Tg2576 control mice, activated microglia in the hippocampus of CHF5074 (125 and 375 ppm/day)-treated Tg2576 mice was significantly $(p<0.001)$ reduced $(-50.2 \pm$ $5.2 \%$ and $-45.5 \pm 4.5 \%$, respectively). On the contrary,
DAPT treatment did not affect activated microglia in Tg2576 mice (+ $19.3 \pm 18.0 \%$ increase).

\section{Dendritic spine length and density}

Dendritic spine length and density were next evaluated in hippocampal pyramidal neurons of the CA1/CA2 fields by GolgiCox silver impregnation. As shown in Figure 5, a reduction of spine density compared to agematched wild-type animals $(p<0.001)$ was apparent in the hippocampus of vehicle-treated, control Tg2576 mice. In contrast, no significant difference in hippocampal spine length was observed between wild-type and transgenic animals (data not shown). While DAPT fully prevented dendritic spine density reduction in Tg2576 mice, a clear and statistically significant amelioration effect of CHF5074 ( $p=0.046$ compared to vehicle-treated transgenic animals) was only observed at the lower dose (125 ppm/day) of the compound.

\section{Cell cycle functionality}

Cell cycle functionality was then investigated in mature neurons by monitoring the levels of a regulatory molecule such as cyclin A (CycA), detected by immunostaining of neuronal nuclei (NeuN). Representative images from vehicle (A-C) and CHF5074-treated Tg2576 mice (D-F) are reported in Figure 6, where panels B and $E$ refer to $\mathrm{CycA}$, panels $\mathrm{C}$ and $\mathrm{F}$ to $\mathrm{NeuN}$ and panels $\mathrm{A}$ and $\mathrm{D}$ to the merged images. The fraction of CycApositive cells over the total number of NeuN-positive neurons was counted in layers II-III of the medial cerebral cortex. In wild-type and Tg2576 control mice the percentage of CycA-expressing neurons was $8.6 \pm 1.5 \%$ and $47.8 \pm 3.3 \%$, respectively. As shown in Figure 6G, at both 125 and $375 \mathrm{ppm} /$ day doses, CHF5074 reduced the percentage of CycA-positive neurons $(17.6 \pm 1.5 \%$ and $17.8 \pm 1.3 \%$, respectively; $p<0.001$ vs vehicle-treated control Tg2576 mice). DAPT treatment was less effective than CHF5074 in reducing the percentage of CycApositive neurons $(\mathrm{p}<0.05)$, leaving an average $35 \%$ of neurons still positive to CycA immunostaining (Figure 6, panel G).

\section{Discussion}

Age is a major risk factor for $\mathrm{AD}$ and various pathophysiological changes, not all directly related to $A \beta$ accumulation, take place in the ageing brain. Thus, when assessing the preclinical therapeutic efficacy of a candidate $\mathrm{AD}$ modifying drug, it is of the utmost importance that multiple indicators of brain functionality are examined in animal models of $\mathrm{AD}$ at the latest possible age. Furthermore, as most AD-associated changes tend to be irreversible, treatment should be started at a relatively early age, when no (or very few) symptoms of disease are detectable, and carried on in a chronic fashion till 

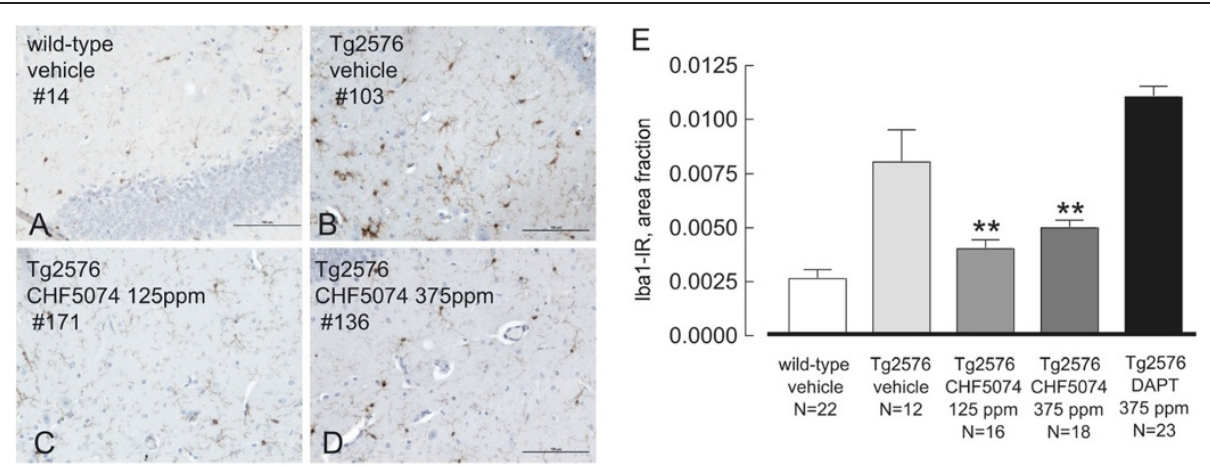

Figure 4 Effect of CHF5074 and DAPT treatments on microglia activation. A-D. Representative images of Iba1-immunostaining of activated microglia in hippocampus sections from wild-type (A) and Tg2576 vehicle- (B) and CHF5074-(C, D)-treated animals; \# indicates the animal code. E. Quantification of Iba1-immunostaining of activated microglia in the different treatment groups. CHF5074, but not DAPT, reduces the level of microglial activation observed in Tg2576 mice. ${ }^{* *} p<0.01$ vs vehicle-treated Tg2576 mice.

very late age (i.e. under conditions in which drug tolerability and lack of detrimental side-effects may become a major concern). Based on this background, in the present study the effects of chronic treatments with the nonsteroidal anti-inflammatory $\gamma$-secretase modulating compound CHF5074 or the $\gamma$-secretase blocker compound DAPT on cognitive performance as well as on several distinct post-mortem indicators of brain functionality and neurodegeneration have been compared in a transgenic mouse model of AD.

The present findings indicate that CHF5074, continuously administered for 13 months at 125 and $375 \mathrm{ppm} /$ day doses, appears to be well tolerated by both wild-type and $\operatorname{Tg} 2576$ animals. In line with this observation, CHF5074, which is under development for the prevention and treatment of $\mathrm{AD}$, displayed a safe and well tolerated profile, as established in an ascending dose regimens, double-blind, placebo-controlled, parallel group study [34]. At marked variance with $\gamma$-secretase blockers, here typified by DAPT (but see also e.g., [35]), no trends towards deleterious effects across different dosing cohorts on both "paper and pencil" and computerized cognitive tests have been described so far for CHF5074 [36].

Previous studies indicated that CHF5074 treatment may attenuate or reverse contextual memory deficit when given acutely [22] or chronically (8-month treatment) [21] to young $\operatorname{Tg} 2576$ mice. A reduction of spatial memory deficit was similarly observed following chronic treatment in a different mouse model of AD (TADS-41) [19]. A reversal of object recognition memory as well as hippocampal plasticity deficits was also observed upon CHF5074 subchronic treatment of young Tg2576 mice [22]. In this study we extended these observations by demonstrating the efficacy of a further prolonged (13 months) treatment with CHF5074 (375 ppm/day) in reversing object recognition memory deficit in $\mathrm{Tg} 2576$
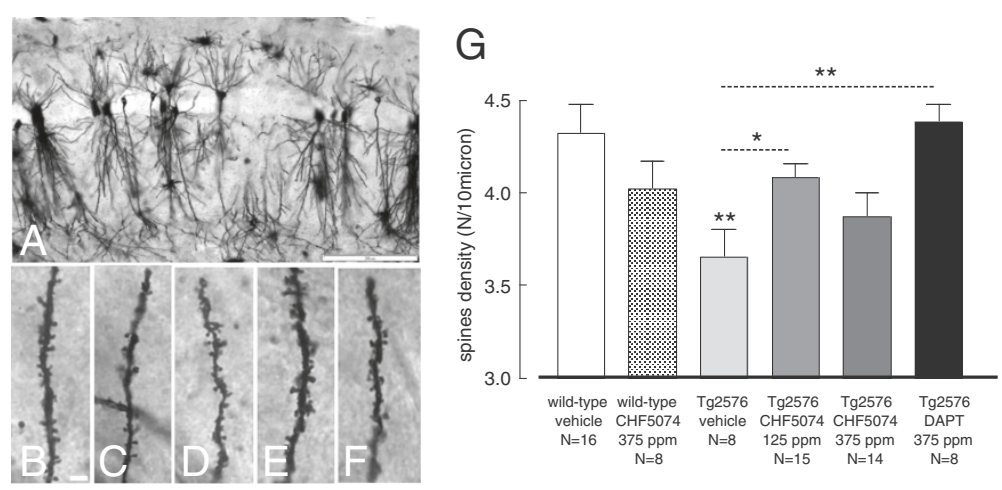

Figure 5 Effect of CHF5074 and DAPT treatments on dendritic spine density and length in hippocampal pyramidal neurons. Low-power mag of CA1 hippocampal cortex (A) visualized by the Golgi-Cox technique; B-E: high-power mag (100x, 1.35NA) of spine morphology in hippocampal pyramidal neurons of wild-type (B), Tg2576 vehicle- (C), Tg2576 CHF5074 125 ppm- (D), CHF5074 375 ppm- (E) and DAPT 375 ppm- (F) treated mice. G. Quantification of the data, including those related to DAPT treatment, expressed as mean ( \pm SEM) spine density and length of pyramidal neurons from the cerebral cortex of animals belonging to different experimental groups; the number of animals utilized for this analysis is indicated below the bars corresponding to each treatment group. ${ }^{*} p<0.05$; ${ }^{* *} p<0.01$. Bars: A, $200 \mu \mathrm{m} ; \mathrm{B}, 5 \mu \mathrm{m}$. 


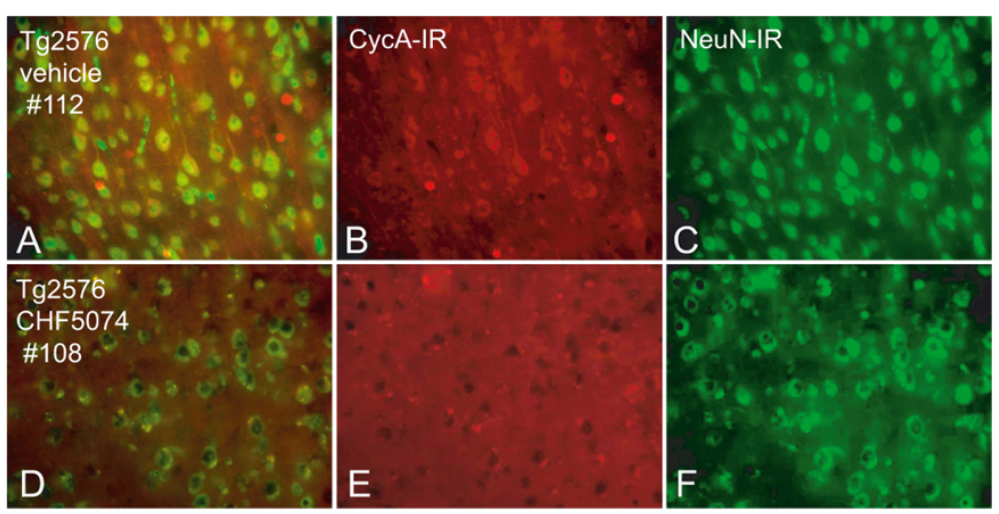

CyA-IR neurons

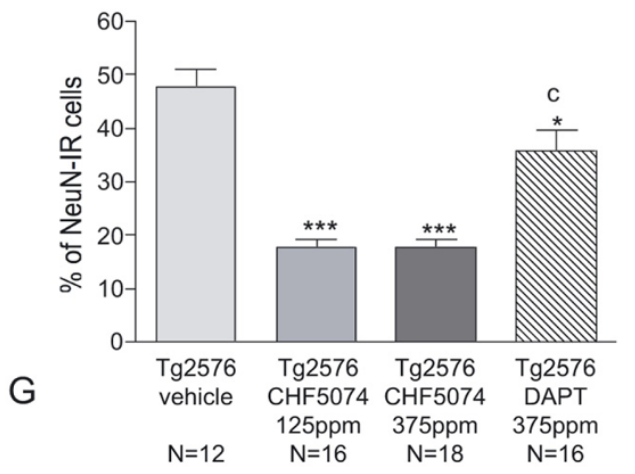

Figure 6 Effect of CHF5074 and DAPT treatments on neuronal cell-cycle functionality. A-F. Representative images of cyclin A immunoreactivity (red staining, B and $\mathbf{E}$ ) in NeuN-positive cells (green staining, $\mathbf{C}$ and $\mathbf{F}$ ) and of the resulting merge images $(\mathbf{A}, \mathbf{D})$ in Tg2576-mice treated with vehicle (A-C) or with CHF5074 375 ppm (D-F); \# indicates the animal code. G. Quantification of cyclin-A positive cells versus total NeuN-positive cells in the different treatment groups. While approximately 50\% of neurons express Cyclin A in untreated ("vehicle") Tg2576 mice, the percentage of Cyclin A/NeuN-positive neurons is reduced to less than 20\% in CHF5074-treated, but not DAPT-treated, animals. ${ }^{*} p<0.05$ and ${ }^{* * *} p<0.001$ vs vehicle-treated Tg2576 mice; $c p<0.001$ vs CHF5074 125 and 375 ppm-treated Tg2576 mice.

mice at a very old age. This test, which is based on spontaneous animal behavior and does not require any exogenously applied stress, is widely used for memory evaluation in mouse models of AD [37-39]. To our knowledge, no previous study has evaluated the potential efficacy of a candidate AD drug in preventing cognitive deficit at such a late stage of animal life. This finding opens up the possibility that CHF5074 could be beneficial in reducing cognitive impairment also in late $\mathrm{AD}$ provided that treatment is started relatively early in the course of illness. Under the same experimental conditions, DAPT was ineffective in improving visual memory performance. This finding is in line with the previously observed failure of $\gamma$-secretase inhibition to rescue object recognition deficits in APP-overexpressing mice [40] and suggests that some cellular and molecular parameters are differentially affected by CHF5074 and DAPT. This view is further supported by the differential responses of some main pathology markers observed in Tg2576 mice treated with CHF5074 or DAPT (summarized in Table 1).
Four of the biochemical indicators analyzed in the present study directly bear on $A \beta$ and its brain accumulation/mobilization. These include amyloid burden, brain $A \beta$ oligomers, plasma $A \beta$ and intraneuronal APP/ $\mathrm{A} \beta$ levels. Amyloid burden was markedly reduced in CHF5074-, but not in DAPT-treated animals. On the contrary, intraneuronal $A P P / A \beta$ and plasma levels of $A \beta 40$ and $A \beta 42$ were similarly modified by both treatments. The increase of plasma $A \beta$ levels observed after chronic treatment with DAPT appears paradoxical. Although the effects of chronic treatment with DAPT on plasma or brain $A \beta$ levels are not known, it has been observed that treatment of transgenic mice and humans with other gamma-secretase inhibitors (e.g., semagacestat) may cause late rebound effects on plasma $A \beta$ levels [41]. Both CHF5074 and DAPT did not affect A $\beta$ oligomers, either in high-detergent (membrane/intracellularly enriched) or in low-detergent (extracellularly enriched) brain extracts. In the case of CHF5074, the only observed effect was a small, but statistically significant increase in brain $A \beta$ monomers. This effect was magnified in Tg2576 mice 
Table 1 Comparison between the main pathology markers in Tg2576 mice chronically treated either with a $\mathrm{\gamma}$-secretase inhibitor (DAPT) and a mixed $\mathrm{p}$-secretase modulator with anti-inflammatory properties (CHF5074)

\begin{tabular}{lll}
\hline Task/marker & DAPT & CHF5074 \\
\hline Novel object recognition test (recognition index) & unchanged & restored at wild-type level at 375ppm \\
\hline amyloid plaque burden & unchanged & reduced \\
\hline oligomers & & \\
\hline plasma Aß42 & increased & increased at 375ppm \\
\hline intraneuronal A & reduced & reduced \\
\hline microglia activation (Iba1-IR) & unchanged & reduced \\
\hline Dendritic spine density (CA1/2 pyramidal neurons) & restored at wild-type level & increased at 375ppm, compared to Tg2576 vehicle \\
\hline Aberrant cell cycle events (cyclinA-IR neurons) & lightly reduced (-28\%) & strongly reduced (-63\%) \\
\hline
\end{tabular}

Treatments were started in 6 month old rats and protracted for 13 months. Behavioral test was then carried out in 18month old animals, and all post-mortem observation in 19 month old animals.

treated with DAPT, which also caused a statistically significant increase of some $\mathrm{A} \beta$ oligomeric species. Although the reason for this quite unexpected finding is presently unclear, it is conceivable to imagine that given the extremely prolonged treatment duration time this may reflect the "A $\beta$ rise" phenomenon previously observed with DAPT and other $\gamma$-secretase inhibitors in the presence of suboptimal inhibitor and/or CTF $\beta$ concentrations [42]. This point will be clarified in further studies by analyzing accumulation of other $\gamma$-secretase substrates, like CTF, p75, etc.

A 342 -immunoreactivity was detected by single-neuron microdensitometry using the 6E10 and 4G8 monoclonal antibodies as probes. Since the peptide epitopes (AA 1-16) targeted by $6 \mathrm{E} 10$ and $4 \mathrm{G} 8$ are shared by the $A \beta 42$ and the A $\beta 40$ peptides as well as by the APP precursor and the sAPP $\beta$ and CTF $\beta$ cleavage by-products, these antibody can recognize all the above species [33]. Moreover, the possibility that abnormally trafficked APP or CTF $\beta$ (but not sAPP $\beta$, which is extracellularly released) and other APPderived peptides like C99 [43] may also contribute to the immunostaining observed in neurons from Tg2576 mice cannot be ruled out at present. Increasing attention is currently being paid to intraneuronal $\mathrm{A} \beta$, generated via the endosomal system and accumulated in endosomes/ lysosomes, mitochondria and autophagosomes, as an early player in the pathogenesis of $\mathrm{AD}$ [10]. In fact, intraneuronal $A \beta$ accumulation occurs well before the increase of extracellular $A \beta$ [10], it is detectable in plaquefree animals [22], and converging reports indicate a key pathogenetic role of intraneuronal $\beta$-amyloid in neurodegeneration and AD pathology $[44,45]$. For example, the intracellular concentration of $A \beta 42$, the most toxic $A \beta$ variant, in pyramidal (CA1) human neurons has been estimated to be $3 \mu \mathrm{M}$ in the case of sporadic $\mathrm{AD}$ patients, as compared to $660 \mathrm{nM}$ in the case of neurons from control, unaffected subjects [46]. Intraneuronal A $\beta$ severely affects neurons viability $[8,9,47]$ and vulnerability to various neurotoxic challenges [48]. Also, elevated levels of intraneuronal $\mathrm{A} \beta 42$ have been reported to be causally related to the activation of the protein kinases that are responsible for intracellular tau hyperphosphorylation in early stages of the disease $[49,50]$. Moreover, intraneuronal $\mathrm{A} \beta$ accumulation has been shown to play a key role in synapse loss and dysfunction [10,51]. CHF5074 was previously shown to restore the levels of synaptophysin [21], to reduce the accumulation of native hyperphosphorylated tau, and to decrease brain GSK-3 $\beta$ levels, a secondary effect presumably associated with the reduction of intraneuronal $A \beta$ [52], thus suggesting an effect of this molecule on the most relevant molecular players involved in AD pathology.

In both CHF5074- and DAPT-treated animals there was a normalization of dendritic spine density in CA1/2 pyramidal neurons compared to vehicle-treated Tg2576 mice. With the use of two-photon confocal microscopy, DAPT has recently been shown to reduce dendritic spine density when administered acutely to wild-type mice [53]. It should be noted, however, that pharmacological modulation of wild-type and mutated-APP are quite different [54] and that the effect of APP on dendritic spine number is still highly controversial [55]. Moreover, multiple and diverse events, such as intracellular soluble or extracellular fibrillar $A \beta$ levels, or the combination of intracellular soluble $A \beta$ and hyperphosphorylated tau, can lead to dendritic spine loss [56]. Thus, amyloid clearance from neurons and from the brain by CHF5074 and DAPT may positively affect structural aspects of hippocampal circuits (e.g., dendritic spine density), but this is not enough, per se, to sustain cognitive performance, as suggested by the divergent effects of the two drugs on novel object recognition test.

Various dysfunctions, some of which precede cortical atrophy and amyloid plaque deposition, are causally associated with $\mathrm{AD}$ neurodegeneration. These include neuroinflammation, neurite abnormalities leading to dendritic spine loss, neuronal cell death and aberrant cell cycle events. Epidemiological analyses support the notion that intake of nonsteroidal anti-inflammatory drugs (NSAIDs) 
can reduce the risk and delay the onset of AD. In contrast to this positive preventive trend, therapeutic studies testing NSAID efficacy in AD patients have been largely unsuccessful so far [57]. A possible explanation for these disappointing, and apparently controversial results may be a wrong therapeutic time-window. In fact, while the occurrence of plaque-dependent inflammation in $\mathrm{AD}$ has been extensively documented in both human specimens and transgenic animal models of the disease, clinical and experimental evidence for the occurrence of inflammation in preclinical, asymptomatic phases of $\mathrm{AD}$ pathology are scanty [58]. In transgenic mouse models of AD, cerebrovascular inflammation has been reported to occur before plaque deposition [59] and various treatments targeting neuroinflammation have been proved to be effective on cognition maintenance or recovery [57]. Moreover, agedependently enhanced neuroinflammatory processes may play an important role in neuronal death or dysfunction, possibly inducing spine pathology [56] as well as cell cycle alterations [30]. Thus, in the present study the possible anti-neuroinflammatory properties of CHF5074 and DAPT have also been assessed.

As revealed by the present results, while a substantial reduction of microglia activation was observed in CHF5074treated animals, no effect on Iba1 immunostaining was detected following treatment with DAPT. Similar results with CHF5074 were obtained in a previous shorter-term study [21]. These data suggest that, at least under the present experimental conditions, CHF5074, but not DAPT, exerts an anti-neuroinflammatory activity. It should be mentioned that while a partial $\gamma$-secretase inactivation has a protective role on amyloid pathology and inflammation, the genetic ablation of presenilin causes progressive inflammatory responses [60]. Thus, the modulatory $\gamma$-secretase activity exerted by CHF5074 could positively affect initial microglia activation, while blockage of $\gamma$-secretase activity by DAPT is likely to be completely ineffective on this particular target. In line with this view, it has been reported recently that inhibition of lipopolysaccharide-induced $\gamma$-secretase activity by DAPT interferes with immune and anti-inflammatory regulatory pathways in the brain [61], while acute DAPT administration restraints microglia activation $[62,63]$. Recently, it has also been proposed that ibuprofen and its derivatives, including CHF5074, besides reducing $A \beta$ pathology and neuroinflammation, modulate astrocyte reactivity through a Rho-GTPase/PAK/ERKdependent signalling pathway [23]. In keeping with this purported mode of action, we have previously shown that chronic treatment of $\mathrm{Tg} 2576$ mice with CHF5074 causes astrocyte hypertrophy and their accumulation around large $A \beta$ deposits [21] -another mechanism that may contribute to the neuroprotective and functional recovery effects promoted by this compound. This result was also confirmed in this study (Additional file 3: Figure S3). We also observed that DAPT also upregulates GFAP-IR but not Iba1, thus further suggesting that microglia activation is a property of CHF5074.

The anti-neuroinflammatory action produced by chronic treatment with CHF5074 may counteract cell death caused by oxidative damage. Ectopic expression of cell cycle proteins identifies neuronal populations undergoing neurodegeneration [63-65] and aberrant cell cycle events have been detected in $\mathrm{Tg} 2576$ mice starting from 6 months of age. Thus, the marked reduction of cyclin A-positive neurons (from $48 \%$ to 18\%) elicited by CHF5074, but not DAPT, points to a fairly strong neuroprotective effect of the former compound. The mechanisms underlying cell-cycle re-entry and cell-cycle protein expression in $\mathrm{AD}$ neurons are still obscure $[14,65]$. It is worth noting, however, that alterations in brain microglia have been shown to occur concomitantly with the appearance of ectopic cell-cycle events and that NSAIDs prevent, but do not reverse, neuronal cell cycle re-entry in the R1.40 mouse model of $\mathrm{AD}$ [30]. The treatment regimen utilized in this study strongly supports this conclusion. However, microglia activation and neuroinflammation, are also triggered by intraneuronal $\mathrm{A} \beta$ accumulation at an early stage of the disease [66] and, conversely, inflammation negatively affects $A \beta$ efflux from the brain [67]. Thus, the anti-inflammatory and cell cycle normalization properties of CHF5074 combined with its $A \beta$ clearance-promoting effect may explain the superior neuroprotective action of this compound compared to DAPT.

\section{Conclusion}

The present findings suggest that chronic treatment of Tg2576 mice with CHF5074, but not DAPT, effectively prevents $\mathrm{AD}$ symptoms (e.g., plaque accumulation and cognitive impairment) and positively affects various neurodegeneration-related events, some of which may occur earlier than, and be not directly linked to, massive $A \beta$ accumulation. The most significant of the latter effects are a marked quenching of microglia activation and associated neuroinflammation as well as a reduced frequency of anomalous cell cycle re-entry events in affected neurons. Notably, the beneficial effects of CHF5074 remain well detectable till an extremely late age, after a one year-long chronic treatment. The multimodal action of CHF5074 appears to be in line with the increasingly recognized multifactorial nature of $\mathrm{AD}$ pathology, whose treatment can greatly benefit from the ability of candidate therapeutic compounds to act on more than one target $[15,67]$. Taken together, the results of this extensive comparative analysis suggest that a specific subset of effects not so closely related to $A \beta$ accumulation and APP processing may play a crucial role in dictating the outcome of neurodegeneration and 
response to therapy. These less obvious effects, most notably the promotion of glia and neuronal cell cycle homeostasis, may represent key targets for the development and monitoring of second generation AD modifying drugs.

\section{Additional files}

Additional file 1: Figure S2. A, B: Representative images of activated microglia (IBA1 immunostaining) of CA1 hippocampal cortex of Tg2576 vehicle (A) and DAPT (B) treated animals. C, D: Representative images of 6 E10 immunostaining of cerebral cortex of Tg2576 vehicle (C) and DAPT (D) treated animals.

Additional file 2: Figure S1. Representative example of SDS-PAGE fractionation (4-12\% Bis-Tris Midi gradient gel) and immunoblot analysis (primary antibody: 6E10 mAb, 1:500; secondary antibody: goat anti-mouse, IrDye 680-labeled antibody, 1:3000) carried out on "low-detergent", 0.01\% NP40/0.1\% SDS brain extracts (enriched in extracellular A $\beta$ ). Immunereactive bands were visualized by near-infrared fluorescence (Odyssey imager, LI-COR). Non-specific, 6E10 mAb cross-reactive polypeptides (arrow), present in both wild-type and Tg2576 brain extracts, were used as loading controls and internal references for data normalization. Synthetic prefibrillar A $342(n)$ prepared according to Lambert et al. [32], with $n$-values ranging from 1 to 4 (not shown), was used as size standard for electrophoretic analysis. Immune-reactive bands were quantified as "near-infrared fluorescence" (NIRF) arbitrary units (see 'Methods' for additional details).

Additional file 3: Figure S3. Representative images of 6E10 (green) and GFAP- (red) immonostaining in the cerebral cortex of Tg2576 vehicle- (A) and DAPT 375ppm- (B) treated animals. A large number of plaques is observed in both groups, while the GFAP-immunostaining is strongly up-regulated in treated animal. C. semiquantitative evaluation of GFAP immunostaining in the experimental groups. The analysis was performed by evaluating the percentage of plaques surrounded by reactive astrocytes, as evaluated in an area doubling the plaque diameter (see Imbimbo et al.2010, for details). Treated animals show an intense upregulation of GFAP-immunostaining around the plaques. Statisical analysi: one-way ANOVA and Dunnet's post-hoc test. ${ }^{*} p<0.05$; ${ }^{* *} p<0.001$.

\section{Competing interest}

This study was sponsored by Chiesi Farmaceutici, Parma, Italy. Bruno P. Imbimbo and Gino Villetti are employees of Chiesi Farmaceutici. The other authors declare no competing interest.

\section{Authors' contribution}

SS, CM and VB carried out immunohistochemical experiments and related quantification; LL carried out Golgi staining and spine quantification; AG carried out animal experiments; MG was responsable for animal care; MF carried out plasma assays; LF contributed to manuscript preparation; VP and MFB carried out plaque and microglia staining and quantification; GV was responsable for drugs PK and administration schema; ARV and SO performed Abeta oligomer analysis and contributed to manuscript preparation; LG, LC, and BPI have designed the study, performed statistical analysis and wrote the manuscript. All authors read and approved the final manuscript.

\section{Author details}

${ }^{1}$ Department of Veterinary Medicine, University of Bologna, Bologna, Italy. ${ }^{2}$ Health Science and Technologies Interdepartmental Center for Industrial Research (HST-ICIR), University of Bologna, Via Tolara di Sopra 50, Bologna, Ozzano Emilia I-40064, Italy. ${ }^{3}$ IRET Foundation, Via Tolara di Sopra 50, Bologna, Ozzano Emilia 40064, Italy. ${ }^{4}$ Department of Life Sciences and biotechnology, University of Ferrara, Via Fossato di Mortara 17-19, Ferrara, Italy. ${ }^{5}$ Department of Neurosciences, Laboratory of Neuropathology, University of Parma, Via Gramsci 14, Parma 43100, Italy. ${ }^{6}$ Department of Biosciences, Biochemistry and Molecular Biology Unit, Laboratory of Functional Genomics and Protein Engineering, University of Parma, Parma, Italy. ${ }^{7}$ Research \& Development, Chiesi Farmaceutici, Via Palermo 26/A, Parma
43100, Italy. ${ }^{8}$ Present address: Microbiological Laboratory, GlaxoSmithKline Manufacturing Spa, Via Asolana 90, Parma, S.Polo di Torrile 43056, Italy.

Received: 10 September 2012 Accepted: 14 March 2013

Published: 5 April 2013

\section{References}

1. Holtzman DM, Goate A, Kelly J, Sperling R: Mapping the road forward in Alzheimer's disease. Sci Transl Med 2011, 3:114ps48.

2. Selkoe DJ: Resolving controversies on the path to Alzheimer's therapeutics. Nature Med 2011, 17:1060-1065.

3. Mangialasche F, Solomon A, Winblad B, Mecocci P, Kivipelto M: Alzheimer's disease: clinical trials and drug development. Lancet Neurol 2010, 9:702-716.

4. Herrup K: Reimagining Alzheimer's disease - An age-based hypothesis. J Neurosci 2010, 30:16755-16762.

5. Struble RG, Ala T, Patrylo PR, Brewer GJ, Yan XX: Is brain amyloid production a cause or a result of dementia of the Alzheimer's type? J Alzheimers Dis 2010, 22:393-399.

6. Karran E, Mercken M, De Strooper B: The amyloid cascade hypothesis for Alzheimer's disease: an appraisal for the development of therapeutics. Nature Rev Drug Discov 2011, 10:698-712.

7. Castellani RJ, Smith MA: Compounding artefacts with uncertainty, and an amyloid cascade hypothesis that is 'too big to fail'. J Pathol 2011, 224:147-152.

8. Hu X, Crick SL, Bu G, Frieden C, Pappu RV, Lee JM: Amyloid seeds formed by cellular uptake, concentration, and aggregation of the amyloid- $\beta$ peptide. Proc Natl Acad Sci USA 2009, 106:20324-20329.

9. Friedrich RP, Tepper K, Ronicke R, Soom M, Westermann M, Reymann K, Kaether C, Fandrich M: Mechanism of amyloid plaque formation suggests an intracellular basis of A $\beta$ pathogenicity. Proc Natl Acad Sci USA 2010, 107:1942-1947.

10. Gouras GK, Tampellini D, Takahashi RH, Capetillo-Zarate E: Intraneuronal $\beta$-amyloid accumulation and synapse pathology in Alxheimer's disease. Acta Neuropathol 2010, 119:523-541.

11. Spire $T L$, Hyman BT: Neuronal structure is altered by amyloid plaques. Rev Neurosci 2004, 15:267-278.

12. Spire TL, Meyer-Luehmann M, Stern EA, McLean PJ, Skoch J, Nguyen PT, Bacskai BJ, Hyman BT: Dendritic spine abnormalities in APP transgenic mice demonstrated by gene transfer and intravital multiphoton microscopy. J Neurosci 2005, 25:7278-7287.

13. Arendt T: Synaptic degeneration in Alzheimer's disease. Acta Neuropathol 2009, 118:167-179.

14. Bonda DJ, Lee H-P, Kudo W, Zhu X, Smith MA, Lee H-G: Pathological implications of cell cycle re-entry in Alzheimer disease. Expert Rev Mol Med 2010, 12:e19.

15. Bajda M, Guzior N, Ignasik M, Malawska B: Multi-target-directed ligands in Alzheimer's disease treatment. Curr Med Chem 2011, 18:4949-4975.

16. Nizzari M, Thellung S, Corsaro A, Villa V, Pagano A, Porcile C, Russo C, Florio T: Neuorodegeneration in Alzheimer Disease: Role of Amyloid precursor protein and presinilin 1 intracellular signaling. J Toxicol 2012, 2012:187297.

17. Imbimbo BP, Del Giudice E, Cenacchi V, Volta R, Villetti G, Facchinetti F, Riccardi B, Puccini P, Moretto N, Grassi F, Ottonello S, Leon A: In vitro and in vivo profiling of CHF5022 nd CHF5074 two beta-amyloid 1-42 lowering agents. Pharmacol Res 2007, 55:318-328.

18. Wolfe MS: $\gamma$-Secretase inhibitors and modulators for Alzheimer's disease. J Neurochem 2012, 120(Suppl 1):89-98.

19. Imbimbo BP, Hutter-Paier B, Villetti G, Facchinetti F, Cenacchi V, Volta R, Lanzillotta A, Pizzi M, Windisch M: CHF5074, a novel gamma-secretase modulator, attenuates brain beta-amyloid pathology and learning deficit in a mouse model of Alzheimer's disease. Br J Pharmacol 2009, 156:982-993.

20. Imbimbo BP, Del Giudice E, Colavito D, D'Arrigo A, Dalle Carbonare M, Villetti G, Facchinetti F, Volta R, Pietrini V, Baroc MF, Serneels L, De Strooper B, Leon A: 1-(3',4'-Dichloro-2-fluoro[1,1'-biphenyl]-4-yl)cyclopropanecarboxylic acid (CHF5074), a novel gamma-secretase modulator, reduces brain beta-amyloid pathology in a transgenic mouse model of Alzheimer's disease without causing peripheral toxicity. J Pharmacol Exp Ther 2007, 323:822-830. 
21. Imbimbo BP, Giardino L, Sivilia S, Giuliani A, Gusciglio M, Pietrini V, Del Giudice E, D'Arrigo A, Leon A, Villetti G, Calzà L: CHF5074, a novel gammasecretase modulator, restores hippocampal neurogenesis potential and reverses contextual memory deficit in a transgenic mouse model of Alzheimer's disease. J Alzheimers Dis 2010, 20:159-173.

22. Balducci C, Mehdawy B, Mare L, Giuliani A, Lorenzini L, Sivilia S, Giardino L, Calzà L, Lanzillotta A, Sarnico I, Pizzi M, Usiello A, Viscomi AR, Ottonello S, Villetti G, Imbimbo BP, Nisticò G, Forloni G, Nisticò R: The $y$-secretase modulator CHF5074 restores memory and hippocampal synaptic plasticity in plaque-free Th2576 mice. J Alzheimers Dis 2011, 24:799-816.

23. Lichtenstein MP, Carriba P, Baltrons MA, Wojciak-Stothard B, Peterson JR, Garcia A, Galea E: Secretase-independent and RhoGTPase/PAK/ERKdependent regulation of cytoskeleton dynamics in astrocytes by NSAIDs and derivatives. J Alzheimers Dis 2010, 22:1135-1155.

24. Lanz TA, Himes CS, Pallante G, Adams L, Yamazaki S, Amore B, Merchant KM: The gamma-secretase inhibitor N-[N-(3,5-difluorophenacetyl)-Lalanyl]-S-phenylglycine t-butyl ester reduces $\mathrm{A}$ beta levels in vivo in plasma and cerebrospinal fluid in young (plaque-free) and aged (plaque-bearing) Tg2576 mice. J Pharmacol Exp Ther 2003, 305:864-871.

25. Hsiao K, Chapman P, Nilsen S, Eckman C, Harigaya Y, Younkin S, Yang F, Cole G: Correlative memory deficits, Abeta elevation, and amyloid plaques in transgenic mice. Science 1996, 274:99-102.

26. Dovey HF, John V, Anderson JP, Chen LZ, de Saint Andrieu P, Fang LY, Freedman SB, Folmer B, Goldbach E, Holsztynska EJ, Hu KL, Johnson-Wood KL, Kennedy SL, Kholodenko D, Knops JE, Latimer LH, Lee M, Liao Z, Lieberburg IM, Motter RN, Mutter LC, Nietz J, Quinn KP, Sacchi KL, Seubert PA, Shopp GM, Thorsett ED, Tung JS, Wu J, Yang S, Yin CT, Schenk DB, May PC, Altstiel LD, Bender MH, Boggs LN, Britton TC, Clemens JC, Czilli DL, Dieckman-McGinty DK, Droste JJ, Fuson KS, Gitter BD, Hyslop PA, Johnstone EM, Li WY, Little SP, Mabry TE, Miller FD, Audia JE: Functional gammasecretase inhibitors reduce beta-amyloid peptide levels in brain. J Neurochem 2001, 76:173-181.

27. Paxinos G, Franklin KBJ: The Mouse Brain in Stereotaxic Coordinates. 2nd edition. San Diego: Academic Press; 2001.

28. Middei S, Restivo L, Caprioli A, Aceti M, Ammassari-Teule M: Region-specific changes in the microanatomy of single dendritic spines over time might account for selective memory alterations in ageing hAPPsweTg2576 mice, a mouse model for Alzheimer disease. Neurobiol Learn Mem 2008, 90:467-471.

29. Knafo S, Libersat F, Barkai E: Dynamics of learning-induced spine redistribution along dendrites of pyramidal neurons in rats. Eur J Neurosci 2005, 21:927-935.

30. Varvel NH, Bhaskar K, Kounnas MZ, Wagner SL, Yang Y, Lamb BT, Herrup K: NSAIDs prevent, but do not reverse, neuronal cell cycle reentry in a mouse model of Alzheimer disease. Clin Invest 2009, 119:3692-3702.

31. Lesné S, Koh MT, Kotilinek L, Kayed R, Glabe CG, Yang A, Gallagher M, Ashe $\mathrm{KH}$ : A specific amyloid-beta protein assembly in the brain impairs memory. Nature 2006, 440:352-357.

32. Lambert MP, Viola KL, Chromy BA, Chang L, Morgan TE, Yu J, Venton DL, Krafft GA, Finch CE, Klein WL: Vaccination with soluble Abeta oligomers generates toxicity-neutralizing antibodies. J Neurochem 2011, 79:595-605.

33. Aho L, Pikkarainen M, Hiltunen M, Leinonen $\mathrm{V}$, Alafuzoff I: Immunohistochemical visualization of amyloid-beta protein precursor and amyloid-beta in extra- and intracellular compartments in the human brain. J Alzheimer Dis 2010, 20:1015-1028

34. Imbimbo BP, Ottonello S, Frisardi V, Solfrizzi V, Greco A, Seripa D, Pilotto A, Panza F: Solanezumab for the treatment of mild-to-moderate Alzheimer's disease. Expert Rev Clin Immunol 2012, 8:135-149.

35. Schor NF: What the halted phase III $\gamma$-secretase inhibitor trial may (or may not) be telling us. Ann Neurol 2011, 69:237-239.

36. Mouri A, Noda Y, Hara H, Mizoguchi H, Tabira T, Nabeshima T: Oral vaccination with a viral vector containing Abeta cDNA attenuates agerelated Abeta accumulation and memory deficits without causing inflammation in a mouse Alzheimer model. FASEB J 2007, 21:2135-2148.

37. Scholtzova H, Wadghiri YZ, Douadi M, Sigurdsson EM, Li YS, Quartermain D Banerjee P, Wisniewski T: Memantine leads to behavioral improvement and amyloid reduction in Alzheimer's-disease-model transgenic mice shown as by micromagnetic resonance imaging. J Neurosci Res 2008, 86:2784-2791.

38. Balducci C, Beeg M, Stravalaci M, Bastone A, Sclip A, Biasini E, Tapella L, Colombo L, Manzoni C, Borsello T, Chiesa R, Gobbi M, Salmona M, Forloni G:
Synthetic amyloid-beta oligomers impair long-term memory independently of cellular prion protein. Proc Natl Acad Sci USA 2010, 107:2295-2300.

39. Dewachter I, Reversé D, Caluwaerts N, Ris L, Kuipéri C, Van den Haute C, Spittaels K, Umans L, Serneels L, Thiry E, Moechars D, Mercken M, Godaux E, Van Leuven F: Neuronal deficiency of presenilin 1 inhibits amyloid plaque formation and corrects hippocampal long-term potentiation but not a cognitive defect of amyloid precursor protein [V717l] transgenic mice. J Neurosci 2002, 22:3445-3453.

40. Burton CR, Meredith JE, Barten DM, Goldstein ME, Krause CM, Kieras CJ, Sisk L, Iben LG, Polson C, Thompson MW, Lin XA, Corsa J, Fiedler T, Pierdomenico M, Cao Y, Roach AH, Cantone JL, Ford MJ, Drexler DM, Olson RE, Yang MG, Bergstrom CP, McElhone KE, Bronson JJ, Macor JE, Blat Y, Grafstrom RH, Stern AM, Seiffert DA, Zaczek R, Albright CF, Toyn JH: The amyloid-beta rise and gamma-secretase inhibitor potency depend on the level of substrate expression. J Biol Chem 2008, 28:22992-23003.

41. Imbimbo BP, Peretto I: Semagacestat, a $\gamma$-secretase inhibitor for the potential treatment of Alzheimer's disease. Curr Opin Investig Drugs 2009, 10:721-730.

42. D'Andrea MR, Nagele RG, Wang HY, Lee DH: Consistent immunohistochemical detection of intracellular beta-amyloid42 in pyramidal neurons of Alzheimer's disease. enthorinal cortex. Neurosci Lett 2002, 333:163-166.

43. Lauritzen I, Pardossi-Piquard R, Bauer C, Brigham E, Abraham JD, Ranaldi S, Fraser P, St-George-Hyslop P, Le Thuc O, Espin V, Chami L, Dunys J, Checler $F$ : The $\beta$-secretase-derived $C$-terminal fragment of $\beta A P P, C 99$, but not $A \beta$, is a key contributor to early intraneuronal lesions in triple-transgenic mouse hippocampus. J Neurosci 2012, 32:16243-55a.

44. Echeverria V, Cuello AC: Intracellular A-beta amyloid, a sign for worse things to come? Mol Neurobiol 2002, 26:299-316.

45. Hashimoto M, Bogdanovic N, Volkmann I, Aoki M, Winblad B, Tjernberg LO: Analysis of microdissected human neurons by a sensitive ELISA reveals a correlation between elevated intracellular concentrations of $A \beta 42$ and Alzheimer's disease neuropathology. Acta Neuropathol 2010, 119:543-554.

46. Umeda T, Tomiyama T, Sakama N, Tanaka S, Lambert MP, Klein WL, Mori H: Intraneuronal amyloid $\beta$ oligomers cause cell death via endoplasmic reticulum stress, endosomal/lysosomal leakage, and mitochondrial dysfunction in vivo. J Neurosci Res 2011, 89:1031-1042.

47. Crews L, Masliah E: Molecular mechanisms of neurodegeneration in Alzheimer's disease. Hum Mol Genet 2010, 19:R12-R20.

48. Bramham CR: Local protein synthesis, actin dynamics, and LTP consolidation. Curr Opinion Neurobiol 2008, 18:524-531.

49. Townsend M, Qu Y, Gray A, Wu Z, Seto T, Hutton M, Shearman MS, Middleton RE: Oral treatment with a gamma-secretase inhibitor improves long-term potentiation in a mouse model of Alzheimer's disease. J Pharmacol Exp Ther 2010, 333:110-119.

50. Takahashi RH, Milner TA, Li F, Nam EE, Edgar MA, Yamaguchi H, Beal MF, Xu $H$, Greengard P, Gouras GK: Intraneuronal Alzheimer abeta42 accumulates in multivesicular bodies and is associated with synaptic pathology. Am J Pathol 2002, 161:1869-1879.

51. Bittner T, Fuhrmann M, Burgold S, Jung CK, Volbracht $C$, Steiner $H$ Mitteregger G, Kretzschmar HA, Haass C, Herms J: Gamma-secretase inhibition reduces spine density in vivo via an amyloid precursor protein-dependent pathway. J Neurosci 2009, 29:10405-10409.

52. Lanzillotta A, Sarnico I, Ingrassia R, Boroni F, Branca C, Benarese M, Faraco G, Blasi F, Chiarugi A, Spano P, Pizzi M: The $\mathrm{\gamma}$-secretase modulator CHF5074 reduces the accumulation of native hyperphosphorylated tau in a transgenic mouse model of Alzheimer's disease. J Mol Neurosci 2011, 45:22-31.

53. Hook VY, Kindy M, Hook G: Inhibitors of cathepsin B improve memory and reduce beta-amyloid in transgenic Alzheimer disease mice expressing the wild-type, but not the Swedish mutant, beta-secretase site of the amyloid precursor protein. J Biol Chem 2008, 283:7745-7753.

54. Jung CK, Herms J: Role of APP for dendritic spine formation and stability. Exp Brain Res 2012, 217:463-470.

55. Bittner T, Fuhrmann M, Burgold S, Ochs SM, Hoffmann N, Mitteregger G, Kretzschmar H, LaFerla FM, Herms J: Multiple events lead to dendritic spine loss in triple transgenic Alzheimer's disease mice. PLoS One 2010, 5:e15477.

56. Heneka MT, Kummer MP, Weggen S, Bulic B, Multhaup G, Münter L, Hüll M, Pflanzner T, Pietrzik CU: Molecular mechanisms and therapeutic 
application of NSAIDs and derived compounds in Alzheimer's disease. Curr Alzheimer Res 2011, 8:115-131.

57. Ferretti MT, Cuello AC: Does a pro-inflammatory process precede Alzheimer's disease and mild cognitive impairment? Curr Alzheimer Res 2011, 8:164-174.

58. Yu D, Corbett B, Yan Y, Zhang GX, Reinhart P, Cho SJ, Chin J: Early cerebrovascular inflammation in a transgenic mouse model of Alzheimer's disease. Neurobiol Aging 2012, PMID:22440674.

59. Nasoohi S, Hemmati AA, Moradi F, Ahmadiani A: The $\gamma$-secretase blocker DAPT impairs recovery from lipopolysaccharide-induced inflammation in rat brain. Neurosci 2012, 210:99-109.

60. Saura CA: Presenilin/gamma-Secretase and inflammation. Front Aging Neurosci 2010, 2:16.

61. Arumugam TV, Chan SL, Jo DG, Yilmaz G, Tang SC, Cheng A, Gleichmann M, Okun E, Dixit VD, Chigurupati S, Mughal MR, Ouyang X, Miele L, Magnus T, Poosala S, Granger DN, Mattson MP: Gamma secretase-mediated Notch signaling worsens brain damage and functional outcome in ischemic stroke. Nature Med 2006, 12:621-623.

62. Vincent I, Pae Cl, Hallows JL: The cell cycle and human neurodegenerative disease. Prog Cell Cycle Res 2003, 5:31-41.

63. Yang Y, Herrup K: Cell division in the CNS: protective response or lethal event in post-mitotic neurons? Biochim Biophys Acta 2007, 1772:457-466.

64. Lee H-G, Casadesus G, Zhu X, Castellani RJ, McShea A, Perry G, Petersen RB, Bajic V, Smith MA: Cell cycle re-entry mediated neurodegeneration and its treatment role in the pathogenesis of Alzheimer's disease. Neurochem Int 2009, 54:84-88.

65. Ferretti MT, Bruno MA, Ducatenzeiler A, Klein WL, Cuello AC: Intracellular $A \beta$-oligomers and early inflammation in a model of Alzheimer's disease. Neurobiol Aging 2012, 33:1329-1342.

66. Erickson MA, Hartvigson PE, Morofuji Y, Owen JB, Butterfield D, Banks WA: Lipopolysaccharide impairs amyloid beta efflux from brain: altered vascular sequestration, cerebrospinal fluid reabsorption, peripheral clearance and transporter function at the blood-brain barrier. J Neuroinflammation 2012, 9:150.

67. Lu JJ, Pan W, Hu YJ, Wang YT: Multi-target drugs: the trend of drug research and development. PLoS One 2012, 7:e40262.

doi:10.1186/1471-2202-14-44

Cite this article as: Sivilia et al: Multi-target action of the novel antiAlzheimer compound CHF5074: in vivo study of long term treatment in Tg2576 mice. BMC Neuroscience 2013 14:44

\section{Submit your next manuscript to BioMed Central and take full advantage of:}

- Convenient online submission

- Thorough peer review

- No space constraints or color figure charges

- Immediate publication on acceptance

- Inclusion in PubMed, CAS, Scopus and Google Scholar

- Research which is freely available for redistribution 